\title{
Priority Areas in Nigeria's Maritime Sector: Developing Agenda for Research
}

\section{Donatus Eberechukwu Onwuegbuchunam}

Department of Maritime Management Technology, Federal University of Technology, Owerri, Nigeria

\section{Email address:}

don@futo.edu.ng

\section{To cite this article:}

Donatus Eberechukwu Onwuegbuchunam. Priority Areas in Nigeria's Maritime Sector: Developing Agenda for Research. International Journal of Transportation Engineering and Technology. Vol. 5, No. 3, 2019, pp. 60-67. doi: 10.11648/j.ijtet.20190503.13

Received: May 23, 2019; Accepted: October 7, 2019; Published: October 23, 2019

\begin{abstract}
This paper proposes research agenda to identify research priority areas in Nigeria's maritime sector.. The aim is twofold: to systematically identify and evaluate critical areas in the maritime sector as basis for optimized investments in human and material resources and secondly based on our findings, propose policy response models that could be applied to resolve impacts of random developments in international shipping environment on Nigeria's maritime sector. The main research agenda items addressed in this paper included: port infrastructural facilities, shipping outputs, ship repair service capacity, maritime clusters, offshore shipping service demands, pollution management and manpower needs in the industry. Risk management strategies for commercial shipping operation and critical transport infrastructure/logistics supply chains were also discussed. Specifically, modelling techniques and models that could be employed for empirical studies on the identified areas were proposed.
\end{abstract}

Keywords: Maritime Infrastructure, Offshore Logistics, Supply Chain, Emission Trading, Manpower Capacity, Risk Models

\section{Introduction}

The maritime sector includes all enterprises engaged in the business of designing, constructing, manufacturing, acquiring, operating, supplying, repairing and/or maintaining vessels, or component parts thereof; the management and/or operation of shipping lines; stevedoring and customs brokerage services; the management and operation of shipyards, dry docks, harbours, marinas, slipways and marine repair shops; shipping and freight forwarding services and similar enterprises [1]. In addition to shipping, transport and ports services, maritime related enterprises and activities are also concerned with resource exploitation at sea, the leisure/tourism industries, professional business services and the public service [1]. Maritime transport is the mainstay of the economy of most maritime nations. Seventy-five (75\%) of the earth's surface is covered by the oceans. As the saying goes "whoever commands the seas, commands trade of the world; whoever commands the trade of the world, commands the riches of the world and consequently the world itself" (Sir. Walter Raleigh, 1552-1682, cited in [2]).

Nigeria is endowed with vast natural gas and crude oil reserves. Her natural gas reserves are put at more than 166 TSCF (Trillion Standard Cubic Feet) and its recoverable crude oil reserves estimated at 28.5 billion barrels. By current global ranking, Nigeria is the world's $10^{\text {th }}$ largest reserves at about 25 billion barrels [3]. Thus, the volume of Nigeria's oil/gas reserves represents veritable sources of maritime export cargo. Again, given its attributes as a maritime nation: extensive coastline spanning $853 \mathrm{~km} \mathrm{[4],}$ ports, rail, road and pipeline transport infrastructure, Nigeria possesses the capacity to provide maritime services to West and Central African sub-region in particular and the African continent in general. Thus, the potential of Nigeria's maritime industry to drive its economy through generation of revenue, provision of employment opportunities and other critical services have long been recognised by the Federal Government. As an example, the economic diversification policy of the Federal Government of Nigeria has largely been pursued through public and private sector initiated investments in the maritime sector. On the other hand, maritime shipping environment is continuously modified by regulatory standards from International organizations especially the 
International Maritime Organization (IMO). Domesticating and implementing these standards have brought about introduction of more regulatory measures (often with high cost implications) in Nigeria's maritime sector. In this connection, optimized investment in the sector that is consistent with requirements of international shipping environment can be achieved by focusing on critical areas. Thus, there is need for research efforts focused on identifying critical areas for development in order to fully harness the maritime potentials of Nigeria. Such a study should among other things, consider in detail the following:

i Estimation of maritime transport demand in the tanker, liner shipping trades and other oil \& gas support services.

ii Estimation of volume of offshore maritime logistics/support services

iii Assessment of local shipbuilding and repair capability.

iv Port infrastructure capacity assessment, development and usage optimization

$\mathrm{v}$ Assessment of demand and supply of marine equipment spares.

vi Assessment of commercial and security risks in the maritime sector.

Based on the foregoing, relevant issues which should form the main research interest relate to:

i. Identification of maritime clusters in Nigeria and their impacts on development and growth of maritime sector.

ii. Identification of key indicators of demand for shipbuilding/repair services in Nigeria

iii. Determination of the number and production capacity of existing and operational shipyards in Nigeria and examination of the constraints (if any) facing them.

iv. Estimation of demand for shipbuilding and repair services in Nigeria and other coastal states within the West \& Central African sub-region.

v. Determination of the productivity of shipyards presently servicing the needs of the West and Central African sub-region's maritime shipping.

vi. Appraisal of safety and security requirements of Critical Transport Infrastructure (CTI) in Nigeria.

\section{Proposed Study Areas}

In the following sections, priority areas that deserve research attention are discussed. This discussion covers relevant sub-topics and as well as highlights applicable criteria for necessary empirical evaluations. Again, the discussions may not be exhaustive but rather provide sufficient depth for understanding of main issues of interest in this paper.

\subsection{Demand \& Supply Estimation in the Following Areas}

\subsubsection{Tanker, Bulk and Liner Shipping Services}

Proposed research study should in detail cover the following: i. Estimation of current and future growth in domestically generated cargo traffic: tanker, bulk, liner cargoes and trans-shipment cargoes etc.

ii. Determination of tonnage requirements (number of vessels/types) to match current and future growth in seaborne cargo traffic.

iii. Analysis of port infrastructural requirements (based on results in i \& ii above) and cargo handling methods. Where such analyses are hampered by dearth of data, simulation techniques may be employed for developing models that could be applied for forecasting and other analytical purposes.

iv. In addition to analysis of port infrastructure requirements based on consideration of present and future port traffic, there is need for detailed examination of port-landside related infra and infostructure, since landward facilities (or national infrastructure) should as expected, complement and be synchronized with port infrastructural facilities for efficiency.

It is pertinent to state that adequate port-landside infrastructure is a pre-condition for efficient intermodal and logistics transport services which are now emphasized globally. For example, high premium is now placed on responsive logistics supply chains by multinational companies involved in global manufacturing and services. A seaport is just one link in a logistics supply chain and port landside infra and info-structure the other. Therefore, a comprehensive value chain analysis should be carried out to assess for example, the impact of Nigeria's inland transport mode facilities: the road, rail, pipelines, conveyor system and associated Information and Communication Technology (ICT) facilities on logistics and transport supply chain performance. These facilities are expected to align with the global logistics supply chains. Such a study, as is being proposed here, should also examine the various freight transport and logistics markets (market segmentation analysis) to determine service needs and constraints. This should include: determination of service qualities expected by shippers/consignees (manufacturing firms, service companies etc.); as well as the challenges faced by transport service providers: carriers, freight forwarders etc. Sensitivity analysis should be incorporated in the analysis in order to examine tariff and price elasticities. At the macro level, outputs from such analysis could serve as decision support for formulating sustainable trade facilitation policy. Although body of research that tangentially addresses issues raised here exists, what is required here is more focused empirical investigations.

\subsubsection{Offshore Marine Logistics/Support Services}

The demand for logistics services is growing rapidly especially in the oil and gas sector of Nigeria. Presently there are one thousand, seven hundred and seventy five $(1,775)$ registered firms offering services in the following logistics areas [5];

i. Transportation 
ii. Material handling

iii. Order processing

iv. Warehousing

v. Inventory

vi. Assembling

The gains of logistics outsourcing from client companies (multinationals) to these local firms are eroded by costs arising from delays. These delays emanate from poor information infrastructure, time-consuming customs procedures, absence of intermodal transport networks/connectivity, delayed goods clearance at the ports [6] and security issues etc. Such constraints present research challenges and as a step to solution, would require analysis of logistics services in the oil and gas sector. Research emphasis should therefore be focused on:

i. Determination of demand for logistics services especially in the oil \& gas sector. This should involve analysis of products/service differentiation to identify niche markets.

ii. Assessment of logistics facility constraints with respect to national transport infrastructure presently available to identify present and future needs.

The overall goal here is to identify research based strategies needed to efficiently integrate Nigeria's logistics sector into the global logistics and transport supply chains.

\subsubsection{Marine Equipment Manufacturing Capability}

The objectives of Nigeria's Cabotage \& Inland shipping Act would be difficult to achieve without requisite local marine equipment \& spares production capability. Local production of marine equipment/machinery spare-parts is critical to the viability of the maritime sector as it is currently facing significant competition from other ports in the subregion [7]. Ideally, marine equipment manufacturing firms in Nigeria should possess adequate capacity to produce and supply marine vessel service spares/components for shipyards, shipping companies, ports and other marine services companies in oil \& gas sector. Research efforts in this area should focus on estimation of potential demand and supply of marine equipment/spares needed by the oil and gas sector, shipyards and port industry. The volume and kinds of these components could be estimated from current and historical data on activities in merchandise and oil $\&$ gas sector. In line with Nigeria's local content policy, joint venture partnerships with foreign equipment manufacturers should be encouraged to increase local production capacity and capability through technology transfer and foreign credit facilities etc. The research findings should among other things, identify production capacities of technical partners expected to partner with indigenous firms in development and manufacture of spares locally.

\subsection{Risk Management in Vulnerable Areas}

\subsubsection{Critical Transport and Maritime Infrastructure Systems}

Maritime sector risks include cyber-crimes where malicious attack could be carried out on information systems of public/private organizations through internet or remote private networks. Such risks can result in financial loss, disruption or damage to the reputation of a shipping company due to failure of its information technology system or disaster of national magnitude. Cyber-attacks can be far reaching as cargo, ship and entire shipping industry control system are frequently targeted. Ships are now even more susceptible as they increasingly shift towards automation. Nigeria port's system consists of eight major coastal ports and numerous jetties, buoys and anchorages. Despite, the adoption and implementation of International Ship and Port's Facility Security (ISPS) Code by the Nigeria Government, to the author's knowledge, no comprehensive risk assessment has been carried out on our seaports/terminals. The provisions of the code currently implemented were founded on risk assessment conducted in foreign ports. The need to conduct national risk assessment to identify areas of vulnerability in our port infrastructure and other transport/logistics facilities has become imperative given the present security challenges in Nigeria. The same assessment is advocated for other organizations servicing the port sector. Thus, research agenda in this regard should focus on finding mitigating solutions to peculiar security and safety challenges facing Nigeria's maritime environment.

\subsubsection{Market Based Risks and Management Mechanisms}

In advanced maritime economies, risk management options are in place to sustain merchant shipping and cargo sector (especially freight markets) against vagaries of commercial uncertainties. For example, derivatives markets have been established to enable shippers and shipowners' hedge against freight rates volatility and supply chain uncertainties. Some instruments e.g. Forward Freight Futures, Swaps and Real Options have been developed for use in hedging against transaction risks [8]. Real options are applied to mitigate uncertainties which sources include: exchange rate volatility, demand risk, and unreliable supply [9]. Apart from the intrinsic risk control value, the job creation potential of derivatives market is better imagined than described. Research based models are needed to develop specific financial instruments for a robust and viable capital market for merchant shipping and freight market in Nigeria.

Issues about mitigating pollution arising from commercial shipping operations are gaining traction in global efforts to achieve Sustainable Development Goals (SDGs). In Europe, a trading mechanism is in place for companies constrained to pollute outside permissible carbon emission limits (EU Emissions Trading System, (EU ETS), see European Commission [10], Ellerman, Buchner and Carraro [11]. Establishment of such mechanisms in Nigeria would reinforce efforts made so far in adoption of international standards to shipping practice as well as engender other positive multiplier effects. Thus, research is also needed for example, to quantify the amount of emission in ports and all modes of air and tractive transport. Based on such estimates, a suitable pricing mechanism can be developed for objective 
pollution control management in Nigeria.

\subsection{Manpower Resource Capacity: Planning and Development}

Manpower resource is critical to productivity in Nigeria's maritime industry. Research attention in this area should be focused on taking inventory of what is currently available, followed by critical evaluation in order to determine any short fall in quantity and specific skill sets needed for current and future periods. Anecdotal evidence suggests that it is not clear what specific skills are needed to satisfy demand for manpower resource in Nigeria's maritime industry. There are also for example, questions raised on quality of locally acquired skills by some foreign employers. As some author puts it; "inspite of the Federal Government's modest efforts to secure local and foreign training for indigenous maritime workforce, multinational shipping companies are critical of quality of local manpower in the shipping industry. This is evident in the indifference shown towards employment of locally trained manpower and government's continual colossal waste of foreign exchange to secure oversea training for seafarers". Thus, more than ten (10) years after the enactment of the cabotage shipping act, the Nigeria Maritime industry is still dominated by over $80 \%$ foreigners in terms of manpower and fleet. These companies which engage in international maritime, oil and gas businesses in Nigeria; are paid in international currencies, prefer seafarers with international standards and certification [12]. Presently, Nigeria is populated by diverse maritime educational institutions and other related training centres. These award certificates of competence, diplomas and degrees in areas of seafarer training, maritime administration, engineering and research. The establishment of these institutions can arguably be justified by demand for manpower in the maritime sector. Yet, there are arguments about manpower challenges to attainment of objectives of cabotage shipping policy. As Akpobolokemi [13] puts it, atleast fifty thousand $(50,000)$ seafarers are needed for manning cabotage vessels. Therefore, research (such as proposed here) needs to estimate the size (and skill type) of manpower needed and then match it with supply in specific areas of the maritime industry. To this end, it is important that inventory of what is currently available in terms of quality of manpower and training facilities be taken. The maritime training institutions available locally may lack state of the arts facilities due to funding constraints. Thus, strategies are needed to guide the training of manpower with skills that are consistent with industry standards and demand. These issues border on manpower planning and developments and merit research attention as well.

\section{Proposing Research Methodology}

The methodology discussed in this paper is prescriptive in nature and covers the stated objectives, research approach and some models for addressing applicable research objective. In the sections that follow, we present each research question along with a mathematical model that can be applied in actual modelling process. The models presented in this paper are prescriptive and should where necessary be adapted to suit data and other criteria consistent with the actual research. It is acknowledged here that more robust models than presented in this paper exist and many more can still be built depending on the focus and assumptions of empirical investigation.

\subsection{Estimating Demand and Supply of Cargo/Passenger Traffic}

One main goal of estimating demand and supply (of seaborne traffic) is to produce estimates that would guide future trade and investment policy. Analysis of demand may involve quantitative estimation of volume of freight or passenger based on some causal or independent variables disaggregated by modes, routes, ports etc. Demand can also be assessed in terms of the level of service offered by modes of transport, supply chain links etc. Demand estimation can be modelled using time series models, cross sectional or panel (or longitudinal) models. The time series models based on Box Jenkins techniques such as:

$$
Y_{t}=\alpha+\alpha_{1} Y_{t-1}+\beta_{0} u_{t}+\beta_{1} u_{t-1}+\varepsilon_{t}
$$

where

$\alpha_{1} Y_{t-1}:$ the autorgressive term,

$\beta_{1} u_{t-1}$ : the moving average term

$\alpha$ and $\varepsilon_{t}$ are the intercept and error term respectively.

The Autoregressive and Moving Average equation ARMA defined by $Y_{t}$ can be applied in forecasting the number $Y_{t}$ of vessels or volume of cargo traffic generated in a particular port/routes over time $(\mathrm{t})$. Models which estimate the volume of international seaborne trade between two or more trading partners include the augmented gravity modelto account for other trade related factors other than population mass (Gross Domestic Product, GDP) and distance/impedance (proxied by transport costs) as shown:

$$
\log \left(T_{i j}\right)=\beta_{0}+\beta_{1} \log \left(Y_{i}\right)+\beta_{2} \log \left(Y_{j}\right)+\beta_{3} \log \left(y_{i}\right)+\beta_{4} \log \left(y_{i}\right)+\beta_{5} \log \left(D_{i j}\right)+\beta_{k} \log \sum_{v=1}^{n} X^{v}{ }_{i j}+\varepsilon_{i j}
$$

where $i$ and $j$ denote the exporting and importing country respectively. The dependent variable is the natural logarithm of bilateral merchandise exports $\left(T_{i j}\right)$ in thousands of U.S. dollars from country $i$ to $j$ in a specific period. The basic explanatory variables are the logs of GDPs $\left(Y_{i}\right.$ and $Y_{j}$, respectively), their GDPs per capita ( $y_{i}$ and $y_{j}$, respectively), and their geographic distance $\left(D_{i j}\right)$ (Gert-Jan, Linders, Slangen, De-Groot \& Beugelsdijk, [14]). Other factors like bilateral trade agreements, membership in regional economic integration etc. are captured as $\mathrm{X}_{\mathrm{ij}}$ variables, $\varepsilon_{i j}$ is the error 
term.

\subsection{Estimating Level of Service in Logistics and Supply Chains}

Conjoint analysis is a widely used and established method for measuring preferences. In practice, they are mainly used for price/fare estimation, new product planning, and for customer segmentation. In comparison with other methods, conjoint measurements are a more realistic form of preference measurement with a higher validity. Methods of conjoint analysis yield estimates of attribute trade-offs using a formal model for analysis (Rao and Johnson, [15]). For example, the following model estimates two functions, $U_{1}\left(X_{1}\right)$ and $U_{2}\left(X_{2}\right)$ respectively for the two attributes $X_{1}$ (port charges) and $X_{2}$ (cargo dwell time) in such a way that the sum of various realizations of $U_{1}$ and $U_{2}$ best represent the judged evaluations (Y's) for the n systems.

$$
Y_{i}=U_{1}\left(x_{i 1}\right)+U_{2}\left(x_{i 2}\right)+\text { Error } \quad \mathrm{i}=1,2, \ldots, \mathrm{n}
$$

where

$\mathrm{x}_{\mathrm{i} 1}=$ level of the port charges for the ith shipment port,

$\mathrm{x}_{\mathrm{i} 2}=$ level of the waiting time for the ith shipment port,

$\mathrm{Y}_{\mathrm{i}}=$ preference rating given to the ith shipment port,

$U_{1}(\bullet)=$ partworth function for attribute 1 (port charges), and

$U_{2}(\bullet)=$ partworth function for attribute 2 (cargo dwell time).

\subsection{Estimating Total Cost of Logistics Transport Chain}

The following is based on the work of Beuthe [16] and his formulations are represented under the subheadings shown below:

\section{Transport Costs}

Focusing on the relationship between cost, volume and transport attributes, the transport unit cost function can be written as:

$$
P=P(Q, Z)
$$

where $Q$ is the total of shipments over the period of analysis, say a year, and $Z$ is the vector of characteristics of the specific transport considered (mode, carrier, means or combination thereof). These characteristics are mainly its reliability $R$, safety during transport $S$, transport time $T$, flexibility $F$ and frequency $N$ (Ben- Akiva, Bolduc \& Park, [17]; Beuthe, Bouffioux, Krier \& Mouchart, [18]).

Administrative and Ordering Costs

The ordering cost per unit can be written as

$$
A=A(F)
$$

since it must be a function of the carrier's flexibility of service.

Inventory Costs

Examples include mainly the cost of the cycle stock, the cost of in- transit inventory, and the cost of the safety stock.

Cycle stock

The cost of the cycle stock is

$$
G_{c}=\frac{1}{2} w \cdot q,
$$

where $q=Q / N$ is the ordered consignment size, and $w$ is the yearly inventory cost per unit.

In- transit inventory

Goods are also in inventory during transportation. The cost of that inventory on wheels depends on the transport duration, the consignment value, the rate of interest and insurance cost. For a particular transport solution, the corresponding unit cost can be written as:

$$
G_{t}=v(S) \cdot T,
$$

$v(S)$ includes the inventory cost, the goods depreciation and the pilferage cost per unit of time (a fraction of year); it is a function of the transport safety. $T$ is the average transport duration in fraction of year, which includes the time taken by all transport operations including delays incurred at transfers.

Safety stock

This account for uncertainty linked to the irregular level of demand from day to day and to possible delivery delays; mainly a function of the transport mode characteristics $Z$. It also depends on the value of the good, the rate of interest and insurance cost. It can be estimated as:

$$
G_{s}=w \cdot k \cdot \sigma,
$$

where $w$ is the yearly inventory cost per unit, which depends on the money value of the goods, $k$ is a parameter that depends on the probability of running out of stock a firm is ready to accept (it can be computed on the daily demand distribution), $\mathrm{s}$ is the standard deviation of demand during lead time, and $k . \mathrm{s}$ defines the level of safety stock that is needed. Following Baumol and Vinod, [19], let us assume here a Poisson distribution so that $\sigma$ can be approximated by:

$$
\sigma=[(t+T) Q]^{1 / 2}
$$

Where $(t+T) Q$ is an estimate of the unsatisfied demand that may accumulate during the period $(t+T)$ of maximum lead time, the time between two shipments $(t)$ added to transport time $T$, when an order is just missing a shipment.

We can aggregate all the above elements to compute the total cost of a particular transport chain for a year during which the total flow is $Q$ :

$$
C=P(Q, Z) \cdot Q+A(F) \cdot N+\frac{1}{2} w \cdot Q / N+v(S) \cdot T \cdot Q+w \cdot k \cdot \sigma(Q, Z)=P(Q, Z) \cdot Q+V(Q, Z)
$$


In Equation $10, P . Q$ can be taken as the external part of the total logistic cost which is determined by the transport supply side, the carrier or the shipper's department in charge of the own transport operations [16].

\subsection{Minimizing Cost of Transport}

According to Khooban [20], many different objective functions may be considered for a transportation problem such as minimization of transportation costs, minimization of labour turnover, minimization of risk to a firm or the environment, and minimization of deterioration of perishable goods. Mathematically, this can according to Khooban [20], be expressed as:

$$
\begin{aligned}
& \text { Minimize } \\
& z=\sum_{i=1}^{n} \sum_{j=1}^{m} \sum_{k=1}^{p} c_{i j k} x_{i j k}
\end{aligned}
$$

Subject to

$$
\begin{gathered}
\sum_{j=1}^{n} x_{i j k}=a_{j k}, \sum_{j=1}^{m} x_{i j k}=b_{k i,} \sum_{k=1}^{p} x_{i j k}=e_{i j}, \\
\sum_{j=1}^{m} a_{j k}=\sum_{i=1}^{p} b_{k i,} \sum_{k=1}^{p} b_{k i}=\sum_{j=1}^{m} e_{i j}, \sum_{i=1}^{n} e_{i j}=\sum_{k=1}^{p} a_{j k} \\
\sum_{j=1}^{m} \sum_{k=1}^{p} a_{j k}=\sum_{k=1}^{p} \sum_{i=1}^{n} b_{k i}=\sum_{i=1}^{n} \sum_{j=1}^{m} e_{i j}, \quad x_{i j} \geq 0
\end{gathered}
$$

where

$\mathrm{i}$ is the number of origin points providing type $\mathrm{k}$ of goods, $\mathrm{j}$ is the number of destinations,

$\mathrm{X}_{\mathrm{ijk}}$ is the number of type $\mathrm{k}$ sent from the ith origin to the jth destination,

$\mathrm{c}_{\mathrm{ijk}}$ is the cost of transporting the unit item of the kth from the ith supply point to the jth destination,

$\mathrm{a}_{\mathrm{jk}}$ is the requirement at the jth destination of type $\mathrm{k}$ of goods,

$b_{k i}$ is the availability of type $k$ of goods at the ith supply point,

$\mathrm{e}_{\mathrm{ij}}$ is the total quantity of goods to be sent from the ith supply point to the jth destination.

\subsection{Models for Risk Assessment and Management}

The goal of risk assessment and measurement is to provide policy makers (public and private sector) with administrative instruments for protection of Critical Transport Infrastructure (CTI) (especially ports and logistics supply chains) against security risks, disasters and terrorist attacks etc. Research outcomes in this case may also recommend mitigating measures in event of such incidence. Such risk assessment entails firstly, a preparation of checklist inventory of CTI assets in the maritime sector. The assessment of vulnerability or otherwise of such assets using state of the art risk analysis models. The final outcome would serve as input to development of national security plan (based on local conditions) which could serve as blueprint for private and public sector administrators in implementing security policies in their areas of need. Risk assessment methodologies can be classified under three broad categories viz: Qualitative risk assessment, Semi-quantitative risk assessment and Quantitative risk assessment. In terms of model building, it is pertinent to consider the existing models of risk analysis as basis for adaptation, outright adoption or for comparison where new ones are calibrated. In risk analysis, the likely steps that should inform data collection, processing and model building should include, among others:

i. Provision of comprehensive inventory of critical infrastructure/assets in the port sector.

ii. Provision of checklist of all vulnerable critical port assets.

iii. Determination through simulation, the impact of and spread of damage to such assets in the event of terrorist attack or natural disaster.

iv. Quantification of all costs associated with damage to such assets in the event of national calamity.

v. Construction of risk matrix template for determining the levels of risks involved and the probability of risk occurrence.

vi. Provision of analytical framework for protection against such risks.

vii. Provision of framework for quick response and mitigation in the event of risk occurrence.

viii.Provision of national security plan document for protection of critical port assets against acts of terrorism and natural disasters.

According to Burns [21]; the following standard risk assessment models can be employed with some modification in estimating and managing risks in critical maritime spaces/domains:

\subsubsection{Security Risk Assessment (SRA) Model}

This defines estimated impact of existing threat on a specific critical infrastructure, vulnerable settings and targets etc. Mathematically this can be represented as:

$$
\text { Risk }=P(\text { probability }) * V(\text { Vulnerability }) * D(\text { damage })
$$

Where it is considered that certain risk factors present should be incorporated in risk models; econometric risk model according to Burns [21] can be adopted as shown:

$$
\mathrm{SRA}=\left(L+I+M+I_{i n}+T+S\right)
$$

Where

L: Logistics-supply chain disruption impact.

$I$ : ineffective supply chain link (machinery breakdown, insufficient funds, inability to guard the target, inability to assess most likely scenario on target).

$M:$ the average Maritime Security (MARSEC) level 
within a given time frame.

$I_{\text {in }}$ : Indirect impact (financial, liabilities, loss of production, delays, insurance, etc.)

$T$ : the target attack impact (direct) focused on potential loss of human life, asset damage, etc.

$S$ : the socio-economic impact, including security resources used and social disruption.

\subsubsection{Value at Risk (VaR) Model}

Value At Risk (VaR) model can be applied in estimating the risk vulnerability of a specific target, a critical infrastructure sector, a region, an industry or an entire nation. This model can be applied in modelling all types of risks including all security and supply chain risks. It can be employed for determining possible reduction in values of assets etc. following a security risk incident. Willis, Morral, Kelly \& Medby [22] suggest the consideration of probability distribution of each likely risk, aggregate risk correlation and damage impact in terms of asset valuation when estimating possible value reduction. Hence, the $\mathrm{VaR}$ is represented as shown:

$$
P^{e x t}=1-F_{Z n}^{a s y m p}(-\mathrm{VaR})=\exp \left[-\left(1+\tau\left(\frac{-\mathrm{VaR}+\beta_{\mathrm{n}}}{\alpha_{\mathrm{n}}}\right)\right)^{\frac{1}{\tau}}\right]
$$

The VaR can be calculated to reflect possible damage and value reduction:

$$
\mathrm{VaR}=-\beta_{\mathrm{n}}+\frac{\alpha_{\mathrm{n}}}{\tau}\left[1-\left(-\ln \left(p^{e x t}\right)\right)^{\tau}\right]
$$

\subsubsection{Models for Assessment of Commodity Demand and Supply Risks}

Demand for commodities between trading nations at regional or global level can be influenced by uncertainties which are random in nature and hence fraught with risks. Econometric models with risk parameters have been developed to curtail risk associated with trade/commodity demands. For example, consider energy formular below developed by Dees, Karadeloglou, Kaufmann and Sanchez [23] cited by Burns [21]. This model explains regional/global demand for commodities based on trade agreements, real commodity values and time factors. It incorporates other elements that affect commodity demand such as: technological innovations in smart logistics network of raw materials and services. Others include: value added operations, temperature and quality sensitivity of commodities in question. With minor modifications e.g. inclusion elements associated with seasonal factors, the model can be adapted to assess risks associated with supply of commodities.

$$
\operatorname{Dem}_{\mathrm{i}}=\Phi\left[Y_{i} \frac{V_{\text {com }}}{V_{i}^{D}} E_{i}, \text { time }\right]
$$

Where $\mathrm{Dem}_{\mathrm{i}}$ reflects the commodity demand. $I$ is the number of units per region or nation
$\Phi$ reflects the cumulative distribution function of demand data generating process

$Y_{i}$ stands for real Gross Domestic Product (GDP)

$V_{c o m}$ is the US dollar commodity value.

$E_{i}$ is the rate of exchange compared to the US dollar value.

$V_{i}^{D}$ is the consumer price index (CPI)

Thus, while the above discussion on some risk models is not exhaustive, it provides some scope of what is expected and therefore basis for more elaboration on research of this nature.

\section{Conclusion}

The Maritime industry is critical for economic growth and security sustenance of maritime nations and indeed Nigeria. It is one area that is full of potentials but beset with many challenges. It therefore requires intervention by policy administrators. Thus, empirical methods are required to evaluate priority areas as basis for developing suitable policy framework for management and administration. The object of this paper was to identify and evaluate areas in the Nigeria maritime sector which possess enormous potentials in terms of revenue earning, provision of employment and through multiplier principle affect national transport and logistics efficiency. The need for focused research according to this paper entails determination of what should be done to harness the potentials of this sector and hence address any potential risks facing it. The paper addressed the question on investments, potential risks and prescribed some remedial models for research purposes. The suggestions made in this paper should be regarded as guide for future research and not as outputs based on empirical data collection, analysis and model building. It is expected that urgent research attention be given to the main areas identified in this paper.

\section{References}

[1] Department of Transport, Republic of South Africa (2011), Maritime Sector Skills Development Study, Research Report South, African Maritime Safety Authority (SAMSA).

[2] Vego, M. (2015). Maritime Strategy and Sea Control: Theory and Practice. Routledge.

[3] National Petroleum Investment Management Services (NAPIMS), (2018). Crude Oil Reserves/Production. Available: http://napims.com/crudeoil.html. Accessed 12/5/18

[4] Hydro International (2018). Coastline Migration in Nigeria. Available: https://www.hydrointernational.com/content/article/coastline-migration-innigeria. Accessed 12/5/18.

[5] Business List (2018). Logistics in Nigeria. Available: https://www.businesslist.com.ng/category/logistics.

[6] Omoke, V. \& Onwuegbuchunam, D. E. (2018), Determinants of Inter-port Competition: A Case of Coastal Ports in West Africa. Journal of Shipping and Ocean Engineering (8) 43-53. 
[7] United Nations Conference on Trade and Development (UNCTAD), (2016). Review of Maritime Transport. Available: http://www.unctad.org/en/PublicationsLibrary/rmt2016_en.pdf. Accessed 10/10/17.

[8] Kavussanos, M. \& Visvikis, I. (2006). Shipping freight derivatives: A survey of recent evidence. Maritime Policy \& $\begin{array}{lllll}\text { Management. } & \text { Vol. } 33 & \text { (3). Pp. 233-255. }\end{array}$ $10.1080 / 03088830600783152$.

[9] Zhao, L. \& Huchzermeier, A. (2018), Supply Chain Finance: Integrating Operations and Finance in Global Supply Chains. Springer International Publishing AG, part of Springer Nature. Gewerbestrasse, Switzerland.

[10] European Commission (2012) EU Emissions Trading System (EU ETS): A Cap and Trade System. Available: https://ec.europa.eu/clima/policies/ets_en. Accessed 12/11/17.

[11] Ellerman, D., Buchner, B. K., and Carraro, C. (2007). Allocation in the European Emissions Trading Scheme, Rights, Rents and Fairness. Cambridge University Press, New York.

[12] Okeke, O. (2015). Poor Nigeria Seafarers' Salary as Major Obstacle to Cabotage Act. Available: https://www.linkedin.com/pulse/poor-nigeria-seafarers-salarymajor-obstacle-cabotage-oliver-okeke. Accessed 05/6/17.

[13] Akpobolokemi, P (2012), Maritime: In the Grip of Foreigners. The Nation, Available: https://thenationonlineng.net/maritimein-the-grip-of-foreigners/ Accessed: 14/05/18.

[14] Gert-Jan M. Linders, G. M, Slangen, A., De-Groot, H. L. F \& Beugelsdijk, S. (2005). Cultural and Institutional Determinants of Bilateral Trade Flows. Discussion Paper, Tinbergen Institute for Economic Research, Erasmus Universiteit Rotterdam, Universiteit van Amsterdam, and Vrije Universiteit Amsterdam.

[15] Rao, V. R \& Johnson, S. C (2014) Applied Conjoint Analysis. Springer Heidelberg New York Dordrecht London.

[16] Beuthe, M. (2011). Economics of transport logistics. In Palma, de A., Lindsey, R., Quinet, E. \& Vickerman, R., eds. Handbook of Transport Economics. Edward Elgar Publising Ltd. 15 Lansdown Road, Cheltenham, United Kingdom.

[17] Ben-Akiva, M., D. Bolduc and J. Q. Park, 2008, Discrete choice analysis of shippers' preferences. In M. Ben-Akiva, H. Meersman and E. Van de Voorde, eds, Recent Developments in
Transport Modeling. Bingley, UK: Emerald Group Publishing Ltd., pp. 135-155.

[18] Beuthe M., Ch. Bouffi oux, C. Krier and M. Mouchart, 2008, A comparison of conjoint, multi- criteria, conditional logit and neural network analyses for rank- ordered preference data. In M. Ben- Akiva, H. Meersman and E. Van de Voorde, eds, Recent Developments in Transport Modelling. Bingley, UK: Emerald Group Publishing Ltd., Ch. 9, 157-178.

[19] Baumol, W. J. and H. D. Vinod, 1970, An inventory theoretic model of freight transport demand. Management Science, 16 (7), 413-421.

[20] Khooban, Z. (2011). Transportation, in Logistics Operations and Management: Concepts and Models ( $1^{\text {st }}$ edition) eds. by Farahani, R. Z; Rezapour, S; Kardar, L. (2011). Elsevier, 32 Jamestown Road London NW1 7BY.

[21] Burns, M. (2016), Logistics and Transport Security: A Strategic, Tactical, and Operational Guide to Resilience. Taylor \& Francis group, Boca Raton, London.

[22] Willis, H. H., Morral, A. R., Kelly, T. K., and Medby, J. J. (2005). Estimating Terrorism Risk. The Rand Corporation.

[23] Dees, S., Karadeloglou, P., Kaufmann, R., and Sanchez, M. 2003. Modelling the World Oil Market Assessment of a Quarterly Econometric Model.

\section{Biography}

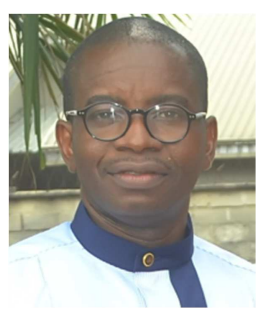

Donatus Eberechukwu Onwuegbuchunam is a Senior Lecturer in the Department of Maritime Management Technology, Federal University of Technology Owerri. He received his B.Tech (Second Class Honours, Upper Division) in Transport Mgt. Technology, M.Sc in Maritime Mgt. Technology and Ph.D. in Maritime Mgt. Technology from the Federal University of Technology, Owerri, Nigeria. He has at various times been Acting Head of Department of Maritime Management Technology and has published many articles in Engineering, Management, Statistics and Econometric journals. 